\title{
Spinal Cord Toll-Like Receptor 4 Mediates Inflammatory and Neuropathic Hypersensitivity in Male But Not Female Mice
}

\author{
Robert E. Sorge, ${ }^{1}$ Michael L. LaCroix-Fralish, ${ }^{1}$ Alexander H. Tuttle, ${ }^{1}$ Susana G. Sotocinal, ${ }^{1}$ Jean-Sebastien Austin, ${ }^{1}$ \\ Jennifer Ritchie, ${ }^{1}$ Mona Lisa Chanda, ${ }^{1}$ Allyson C. Graham, ${ }^{1}$ Lucas Topham, ${ }^{1}$ Simon Beggs, ${ }^{2}$ Michael W. Salter, ${ }^{2}$ \\ and Jeffrey S. Mogil ${ }^{1}$ \\ ${ }^{1}$ Department of Psychology and Alan Edwards Centre for Research on Pain, McGill University, Montreal, Quebec H3A 1B1, Canada, and ${ }^{2}$ Hospital for Sick \\ Children, Department of Physiology, University of Toronto, and University of Toronto Centre for the Study of Pain, Toronto, Ontario M5G 1G6, Canada
}

The innate immune system is increasingly appreciated to play an important role in the mediation of chronic pain, and one molecule implicated in this process is the Toll-like receptor 4 (TLR4). Here, using pharmacological and genetic manipulations, we found that activating TLR4 in the spinal cord, with the agonist lipopolysaccharide (LPS), causes robust mechanical allodynia but only in male mice. Spinal LPS had no pain-producing effect in female mice. TLR4 also has a sex-specific role in inflammatory (complete Freund's adjuvant) and neuropathic (spared nerve injury) pain: pain behaviors were TLR4 dependent in males but TLR4 independent in females. The sex differences appear to be specific to the spinal cord, as LPS administered to the brain or the hindpaw produces equivalent allodynia in both sexes, and specific to pain, as intrathecal LPS produces equivalent hypothermia in both sexes. The involvement of TLR4 in pain behaviors in male mice is dependent on testosterone, as shown by gonadectomy and hormone replacement. We found no sex differences in spinal Tlr4 gene expression at baseline or after LPS, suggesting the existence of parallel spinal pain-processing circuitry in female mice not involving TLR4.

\section{Introduction}

Toll-like receptors (TLRs) are receptors that initiate an immune response through recognition of structurally conserved components of microbes and several endogenous ligands (Erridge, 2010). In the CNS, TLR4 is expressed primarily by microglia (Lehnardt et al., 2003) and is solely responsible for the biological activities of endotoxin lipopolysaccharide (LPS) (Beutler and Poltorak, 2001; Zähringer et al., 2008), a major component of Gram-negative bacteria cell walls. Administration of LPS by various routes produces profound pain hypersensitivity (Wiertelak et al., 1994), which can be blocked by spinally delivered metabolic inhibitors of glia (Meller et al., 1994; Watkins et al., 1997), the TLR4 antagonist FP-1 (Bettoni et al., 2008), or via intrathecal siRNA knockdown of TLR4 (Wu et al., 2010). Supporting a broader role for TLR4 in pain are the observations that TLR4 loss-of-function mutant mice have reduced allodynia and/or hy-

Received July 28, 2011; revised Sept. 8, 2011; accepted Sept. 10, 2011.

Author contributions: R.E.S., M.L.L.-F., S.B., M.WS., and J.S.M. designed research; R.E.S., M.L.L.-F., A.H.T., S.G.S., J.-S.A., J.R., M.L.C., A.C.G., L.T., and S.B. performed research; R.E.S., M.L.L.-F., and J.S.M. analyzed data; R.E.S., M.W.S., and J.S.M. wrote the paper.

This research was supported by the U.S. National Institutes of Health (J.S.M.), Louise and Alan Edwards Foundation (J.S.M.), Canada Research Chairs program (M.W.S., J.S.M.), Howard Hughes Medical Institute (M.W.S.), Canadian Institutes of Health Research (M.W.S., J.S.M.), Krembil Foundation (M.W.S., J.S.M.), and the Ontario Research Foundation (M.W.S.).

Correspondence should be addressed to Dr. Jeffrey S. Mogil, Department of Psychology, McGill University, 1205 Dr. Penfield Avenue, Montreal, QC H3A 1B1, Canada. E-mail: jeffrey.mogil@mcgill.ca.

DOI:10.1523/JNEUROSCI.3859-11.2011

Copyright $\odot 2011$ the authors $\quad 0270-6474 / 11 / 3115450-05 \$ 15.00 / 0$ peralgesia following L5 nerve transection (Tanga et al., 2005) or chronic constriction injury of the sciatic nerve (Bettoni et al., 2008).

Women are greatly over-represented as chronic pain sufferers compared with men, and there is now consensus that this is due, at least in part, to the increased nociceptive sensitivity of women (Greenspan et al., 2007). In addition, a number of qualitative, mechanistic differences in pain processing have been evinced between the sexes, including in humans (Mogil and Bailey, 2010). Despite this, the vast majority of preclinical pain studies use male subjects exclusively (Mogil and Chanda, 2005), and, to our knowledge, this is true of the entire existing TLR4/pain literature to date with only one exception (Lan et al., 2010). Thus, the purpose of this study was to examine whether TLR4 contributes to pain behaviors in both sexes.

\section{Materials and Methods}

Subjects. Experiments were performed on naive, adult (6-12 weeks of age) mice of both sexes. For most experiments, outbred CD-1 (ICR:Crl) mice were bred in-house from breeders obtained from Charles River. The following inbred strains were used, all obtained from The Jackson Laboratory or Charles River: $\mathrm{C} 3 \mathrm{H} / \mathrm{HeJ}, \mathrm{C} 3 \mathrm{H} / \mathrm{HeN}, \mathrm{C} 57 \mathrm{BL} / 10 \mathrm{ScNJ}$ (hereinafter called $\mathrm{B} 10 \mathrm{ScNJ}$ ), and $\mathrm{C} 57 \mathrm{BL} / 10 \mathrm{ScSnJ}$ (hereinafter called B10ScSnJ). $\mathrm{C} 3 \mathrm{H} / \mathrm{HeJ}$ mice are known to have a dominant-negative point mutation in the mouse Tlr4 gene; $\mathrm{C} 3 \mathrm{H} / \mathrm{HeN}$ are the closest wild-type substrain (Poltorak et al., 1998). The B10ScNJ strain has a recessive null mutation of the Tlr4 gene [equivalent to a Tlr4 knock-out mouse (Poltorak et al., 1998)]; the B10ScSnJ strain is the closest to the wild-type strain. Mice were housed with their same-sex littermates (two to four animals per 
cage) in standard shoebox cages, maintained in a temperature-controlled $\left(20 \pm 1^{\circ} \mathrm{C}\right)$ environment $(14 / 10 \mathrm{~h}$ light/dark cycle), and fed (Harlan Teklad 8604) and watered ad libitum.

Gonadectomy and testosterone replacement. Gonadectomized and sham gonadectomized CD-1 mice were purchased from Charles River. Castration and ovariectomy (dorsal approach) surgeries were performed by experienced personnel according to standard protocols no less than 1 week before delivery.

Testosterone propionate was obtained from Sigma, dissolved in polyethylene glycol, and administered via subcutaneously implanted osmotic minipumps (Model 2002, ALZET), at a rate of $0.5 \mu \mathrm{l} / \mathrm{h}$ over $14 \mathrm{~d}$ in a dose of $250 \mu \mathrm{g} / \mathrm{d}$. Mice were anesthetized with isoflurane/oxygen, and osmotic minipumps were implanted via a small $(\sim 1 \mathrm{~cm})$ incision into the upper back. The incision was closed with sterile $9 \mathrm{~mm}$ stainless steel wound clips, and animals were placed in a recovery chamber for $30 \mathrm{~min}$ before being returned to their home cages.

von Frey testing. Mice were placed individually in transparent Plexiglas cubicles $(5 \times 8.5 \times 6 \mathrm{~cm})$ placed upon a perforated metal floor, and habituated for $2 \mathrm{~h}$ before behavioral testing began. Nylon monofilaments $(\approx 0.015-1.3 \mathrm{~g}$; Touch Test Sensory Evaluator Kits 2 to 9, Stoelting) were firmly applied to the plantar surface of each hindpaw until they bowed for 0.5 s. The up-down method of Dixon (Chaplan et al., 1994) was used to estimate $50 \%$ withdrawal thresholds. Where allodynia was produced by CNS injection, the average threshold of both hindpaws was analyzed at each time point.

Lipopolysaccharide. After assessment of baseline mechanical sensitivity, LPS (Escherichia coli serotype 0111:B4, Sigma) was injected intrathecally (0.01-7.5 $\mu \mathrm{g} ; 5 \mu \mathrm{l}$ injection volume) (Hylden and Wilcox, 1980), intracerebroventricularly (1-10 $\mu \mathrm{g} ; 3 \mu \mathrm{l}$ injection volume) (Laursen and Belknap, 1986), or subcutaneously into the plantar surface of one hindpaw (1-5 $\mu \mathrm{g} ; 20 \mu \mathrm{l}$ injection volume). In all cases, mechanical thresholds were retested at $1,2,4,6$, and $24 \mathrm{~h}$ postinjection. Changes in core body temperature produced by intrathecal LPS were measured with a digital rectal thermometer at all time points, immediately following von Frey testing. In one study, intraplantar zymosan $(0.25 \mathrm{mg} / \mathrm{ml} ; 20 \mu \mathrm{l}$ injection volume) was used as a TLR2-specific control.

Inflammatory assay. After testing for baseline mechanical sensitivity on two separate occasions separated by at least $24 \mathrm{~h}$, mice were injected with complete Freund's adjuvant (CFA; $50 \%$, in a $20 \mu$ linjection volume) into one hindpaw. Mice were retested $24 \mathrm{~h}$ later to confirm the presence of mechanical allodynia, and then at several time points after drug injection (see TLR4 antagonist, below).

Neuropathic assay. After testing for baseline mechanical sensitivity on two separate occasions separated by at least $24 \mathrm{~h}$, mice were subjected to a unilateral spared nerve injury (SNI) surgery (Shields et al., 2003). We spared the sural territory, and thus von Frey stimuli were aimed at the lateral aspect of the hindpaw. Mice were retested for mechanical sensitivity on postoperative day 7 , and then at several time points after drug injection (see TLR4 antagonist, below).

TLR4 antagonist. CD-1 mice rendered allodynic via SNI or CFA were administered LPS purified from Rhodobacter sphaeroides (LPS-RS). LPSRS, with an underacylated endotoxin, antagonizes TLR4s competitively and also via inhibition of hexa-acylated endotoxin:MD-2 complexes (Teghanemt et al., 2005). After the demonstration of mechanical allodynia $6 \mathrm{~h}$ after LPS, $4 \mathrm{~h}$ after zymosan, $24 \mathrm{~h}$ after CFA, or $7 \mathrm{~d}$ after SNI (corresponding to the peak of allodynia in each case based on pilot data), mice were injected intrathecally with $2 \mu \mathrm{g}$ of LPS-RS (or saline vehicle) in an injection volume of $5 \mu \mathrm{l}$, and were retested 10, 20,30,60, and $120 \mathrm{~min}$ postinjection.

qPCR. Naive male and female CD-1 mice were used, half given an injection of LPS $(0.1 \mu \mathrm{g}$, i.t.; $n=3 / \mathrm{sex} /$ condition $)$ and killed at $4 \mathrm{~h}$ postinjection. Dorsal hemisected lumbar (L4-L6) spinal cords were removed, and total RNA isolated (TRIzol, Invitrogen) and reverse transcribed. Amplification of Tlr4 (assay ID: Mm00445273_m1) was performed using an ABI 7000 with TaqMan probes and primers as per the manufacturer's protocol, using $n=2-3$ technical replicates. Relative quantification was made following the standard curve method. Results were averaged and normalized by dividing mean values of the Tlr4 gene by mean values of the housekeeping gene Gapdh.
Statistical analyses. Allodynia was quantified as the area over the timewithdrawal threshold curve from 0 to $6 \mathrm{~h}$ postinjection, the time period in which allodynia was to be expected. For each mouse, the area over the curve was calculated using the trapezoidal method, and expressed as a percentage of the maximum possible allodynia (i.e., withdrawal thresholds of $0 \mathrm{~g}$ at all postoperative/postinjection time points). Individual percentage allodynia scores were then averaged among all mice in the group.

Anti-allodynia (i.e., reversal of allodynia by the TLR4 antagonist) was quantified as the maximum observed reversal at any time point, with respect to the level of allodynia displayed immediately preinjection by each animal and the original baseline threshold. This measure was used because we were more interested in the extent of maximal allodynia than its duration.

Data were analyzed in SYSTAT, version 13 (SPSS). In three cases, data points were removed after being identified as statistical outliers (Studentized residuals $>3$ ). In the TLR4 antagonist experiment, two data points were removed because CFA failed to produce measurable allodynia. Multiway ANOVAs or planned contrasts were performed, followed by oneway ANOVAs and Tukey's post hoc test (or Student's $t$ test), as appropriate. A criterion $\alpha$ level of 0.05 was adopted to define statistical significance in all experiments.

\section{Results}

\section{Sex difference in allodynia from spinal LPS}

We found a robust sex difference in the mechanical allodynia produced by intrathecal LPS. Time course data from the $0.1 \mu \mathrm{g}$ LPS dose are shown in Figure 1 $a$. LPS produced clear allodynia in male CD- 1 mice ( $n=7-8 /$ sex/dose) at $1-6 \mathrm{~h}$ postinjection, with a return to baseline withdrawal thresholds by $24 \mathrm{~h}$ (Fig. 1a). Repeated-measures ANOVA revealed a significant time $X \operatorname{sex} \times$ treatment $(0.1 \mu \mathrm{g}$ vs saline $)$ interaction $\left(F_{(5,115)}=10.2, p<\right.$ 0.001). Female CD-1 mice so injected displayed mechanical thresholds at all time points that were indistinguishable from those of saline-treated mice of either sex (Fig. 1a). All percentage maximum allodynia data plotted in Figure $1, b$ and $d-g$, derive from similarly performed experiments; in every case, salinetreated and (where relevant) contralateral hindpaw data were also obtained, but none showed any significant changes from baseline and are not shown.

A two-way ANOVA performed on time-integrated intrathecal dose-response data $(n=4-7 /$ dose/sex $)$ revealed a significant treatment $\times$ sex interaction $\left(F_{(4,49)}=7.6, p<0.001\right)$. The administration of intrathecal LPS over three orders of magnitude revealed that LPS produces no statistically significant mechanical allodynia in female CD-1 mice (main effect of dose in females: $F_{(4,24)}=0.6, p=0.67$ ) (Fig. $1 b$ ). Doses $>10 \mu$ g were associated with mortality and thus were not tested further.

This all-or-nothing sex difference in intrathecal LPS allodynia was not accompanied by sex differences in spinal cord Tlr4 gene expression. A two-way ANOVA revealed only a main effect of LPS $\left(F_{(1,8)}=5.7, p<0.05\right)$. As shown in Figure $1 c$, although we were able to demonstrate LPS-induced increases in Tlr4 mRNA levels $(p<0.05)$, no sex differences were observed either at baseline or after intrathecal LPS ( $p=0.71$ and 0.79 , respectively). Importantly, the upregulation of Tlr4 mRNA by LPS in females indicates that females express functional TLR4 receptors in the spinal cord.

A two-way ANOVA performed in the gonadal hormone experiment (sex $\times$ hormone condition; $n=4-12 /$ sex/condition) revealed a significant sex $\times$ hormone interaction $\left(F_{(2,44)}=16.7\right.$, $p<0.001)$. Testosterone appeared to mediate the sex difference (Fig. $1 d$ ), as castrated CD-1 males were insensitive to LPS ( $0.1 \mu \mathrm{g}$; $p<0.005$ compared with other male groups) and as full LPSinduced allodynia was reinstated by administering testosterone 
propionate to castrated males and ovariectomized females $(p<0.005$ compared with other female groups).

To confirm the TLR4 dependence of allodynia induced by intrathecal LPS, we tested mouse strains with mutant (dominant negative or null mutant) Tlr4 genes along with their wild-type controls. A two-way ANOVA performed on $\mathrm{C} 3 \mathrm{H} / \mathrm{HeN}$ (wild-type) and $\mathrm{C} 3 \mathrm{H} / \mathrm{HeJ}$ (dominant-negative) mice of both sexes ( $n=5 /$ strain/sex) revealed a significant sex $\times$ genotype interaction $\left(F_{(1,16)}=18.2\right.$, $p<0.001)$; robust LPS $(0.1 \mu \mathrm{g})$ allodynia was seen only in $\mathrm{C} 3 \mathrm{H} / \mathrm{HeN}$ males (Fig. 1e). A significant sex $\times$ genotype interaction $\left(F_{(1,28)}=35.4, p<0.001\right)$ was also seen in the B10ScSnJ (wild-type) versus B10ScNJ (null mutant) comparison $(n=$ $5-11 /$ strain/sex), with only B10ScSnJ males displaying robust LPS-induced allodynia (Fig. 1e). A one-sample $t$ test revealed significant allodynia in female B10ScNJ mice, but the allodynia was not significant after correction for multiple comparisons $(p=0.22)$.

This sex difference appears to be restricted to spinal TLR4 mechanisms, as there were no sex differences in allodynia evoked by intracerebroventricular LPS (dose $\times$ sex interaction: $F_{(3,40)}=0.6 ; n=$ $4-8 /$ dose/sex) (Fig. $1 f$ ) or intraplantar LPS (dose $\times$ sex interaction: $F_{(2,18)}=0.1$; $n=4-5 /$ dose/sex) (Fig. $1 g$ ). The sex difference was also restricted to TLR4 pain mechanisms in the spinal cord as males were not different from females in the hypothermia produced by intrathecal LPS (dose $\times$ sex interaction: $F_{(4,49)}=0.9 ; n=$ 4-7/dose/sex) (Fig. 1h).

\section{Antagonist studies of TLR4 mediation of allodynia}

Allodynia produced by various manipulations was challenged with the TLR4 antagonist LPS-RS injected intrathecally into CD- 1 mice ( $n=4-8 /$ condition/sex) of both sexes, at the peak of allodynia in each case (Fig. 2). To confirm TLR-4 specificity of the antagonist under the current experimental conditions, in some cases wild-type $\mathrm{B} 10 \mathrm{ScSnJ}$ and null mutant B10ScNJ male mice were tested as well. No significant sex or genotype differences in allodynia immediately before LPS-RS injection were observed in any case, with the exception that LPS (as before) produced no measurable allodynia in female CD-1 mice (Fig. 2a). For LPS, repeated-measures ANOVA (beginning with the $6 \mathrm{~h}$ post-LPS time point) revealed a significant sex $\times$ repeated measures interaction $\left(F_{(5,80)}=2.9, p<0.05\right)$. In male CD-1 mice, LPS-RS produced complete reversal of LPSinduced allodynia. Zymosan produced robust allodynia in both a LPS $(0.1 \mu \mathrm{g}$, i.t. $)$
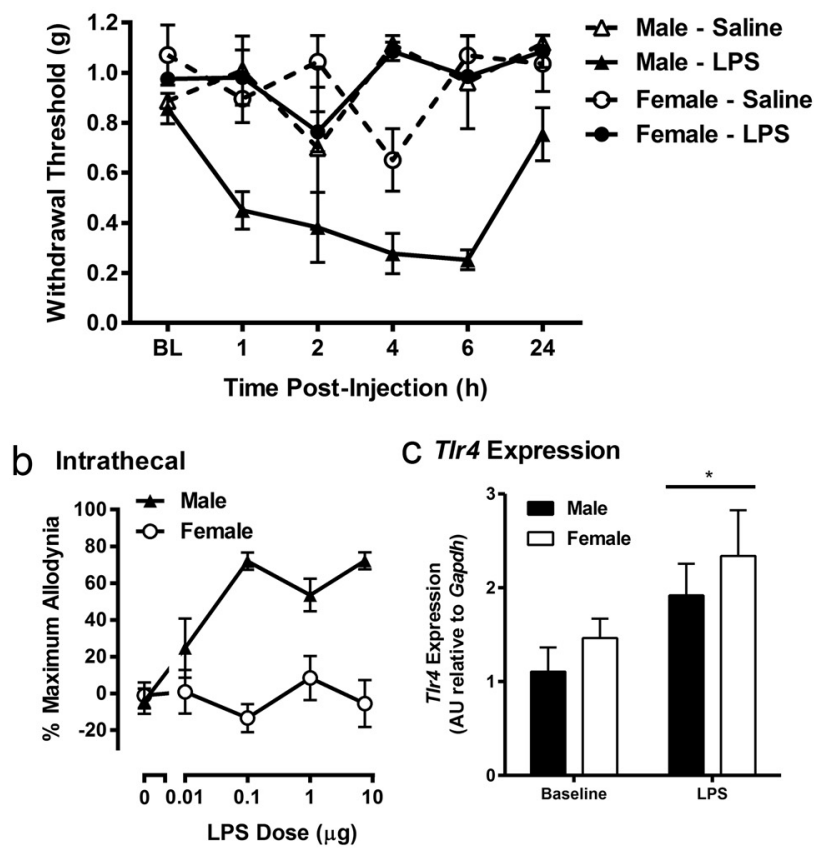

C TIr4 Expression

d Testosterone-Dependence
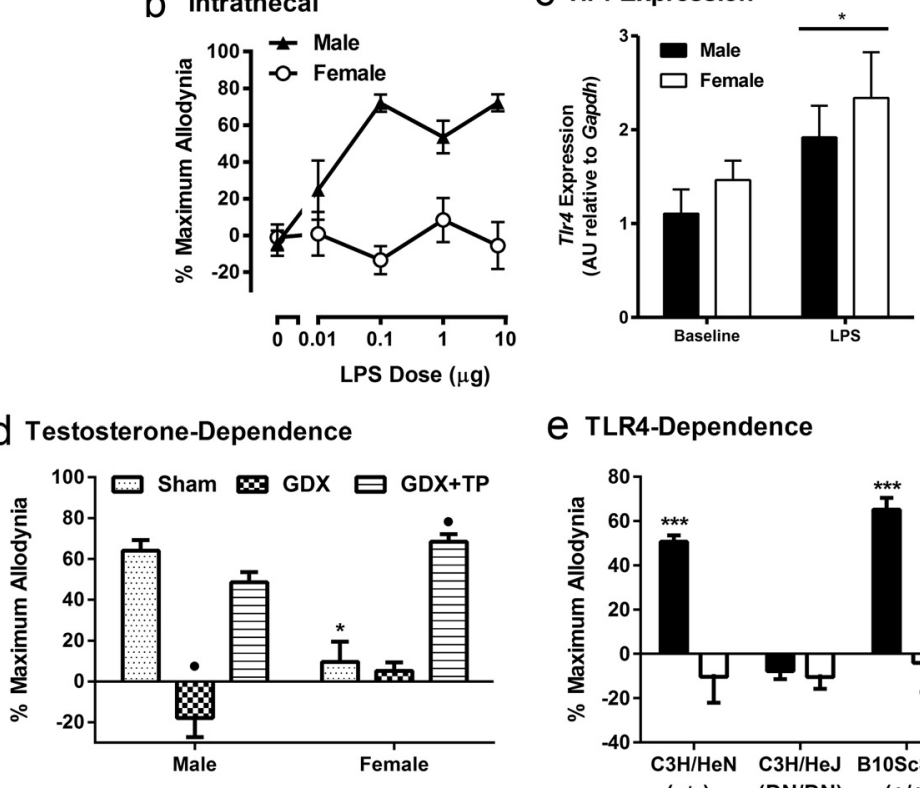

e TLR4-Dependence

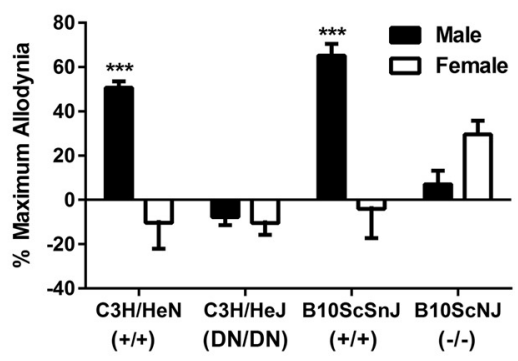

f Intracerebroventricular

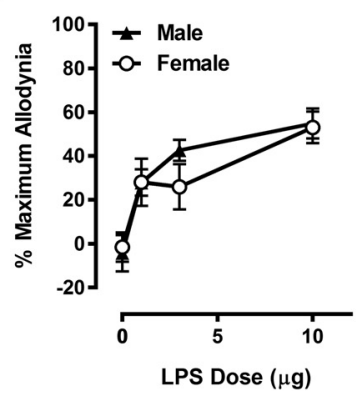

g Intraplantar

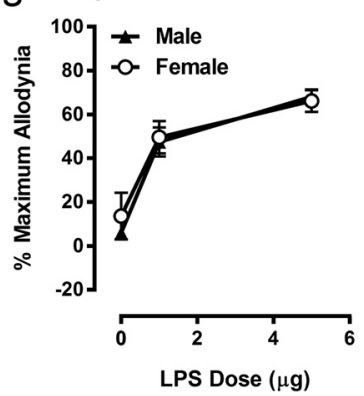

h Hypothermia

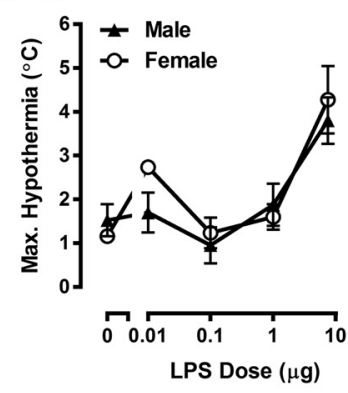

Figure 1. $\boldsymbol{a}-\boldsymbol{c}$, Female CD-1 mice do not exhibit mechanical allodynia after intrathecal LPS administration $(\boldsymbol{a}, \boldsymbol{b})$, despite equivalent levels of T/r4 expression in the spinal cord ( $\boldsymbol{c}$ ). $\boldsymbol{d}$ - $\boldsymbol{h}$, The sex difference is testosterone dependent $(\boldsymbol{d})$ and TLR4 dependent $(\boldsymbol{e})$, and is not seen after intracerebroventricular $(\boldsymbol{f})$ or intraplantar $(\boldsymbol{g})$ LPS injection, nor in hypothermia from intrathecal LPS (h). Symbols in a represent the mean \pm SEM threshold (in grams) to withdraw from von Frey filaments. Symbols or bars in graphs $\boldsymbol{b}$ and $\boldsymbol{d}-\boldsymbol{g}$ represent mean \pm SEM percentages of the maximum possible allodynia (see main text) from time course data collected exactly as shown in graph $\boldsymbol{a}$. Bars in graph crepresent mean spinal cord T/r 4 mRNA expression in arbitrary units (AU) compared with Gapdh. Symbols in graph $\boldsymbol{h}$ represent the mean \pm SEM maximum hypothermia $\left({ }^{\circ} \mathrm{C}\right)$ exhibited by each mouse over the $24 \mathrm{~h}$ testing period. ${ }^{*} p<0.05,{ }^{* * *} p<0.001$ compared with relevant opposite-sex group, or baseline, by $t$ test; ${ }^{\bullet} p<0.05$ compared with all other same-sex groups by Tukey's post hoc test. GDX, Gonadectomy; TP, testosterone propionate. sexes, but this allodynia was not affected by LPS-RS in either sex (Fig. 2b). For CFA, repeated-measures ANOVAs revealed significant interactions with sex among CD-1 mice $\left(F_{(5,35)}=3.7, p<\right.$ $0.01)$ and with $\operatorname{Tl} 4$ genotype $\left(F_{(5,30)}=4.6, p<0.005\right)$; reversal of CFA allodynia was observed only in male CD-1 and male 

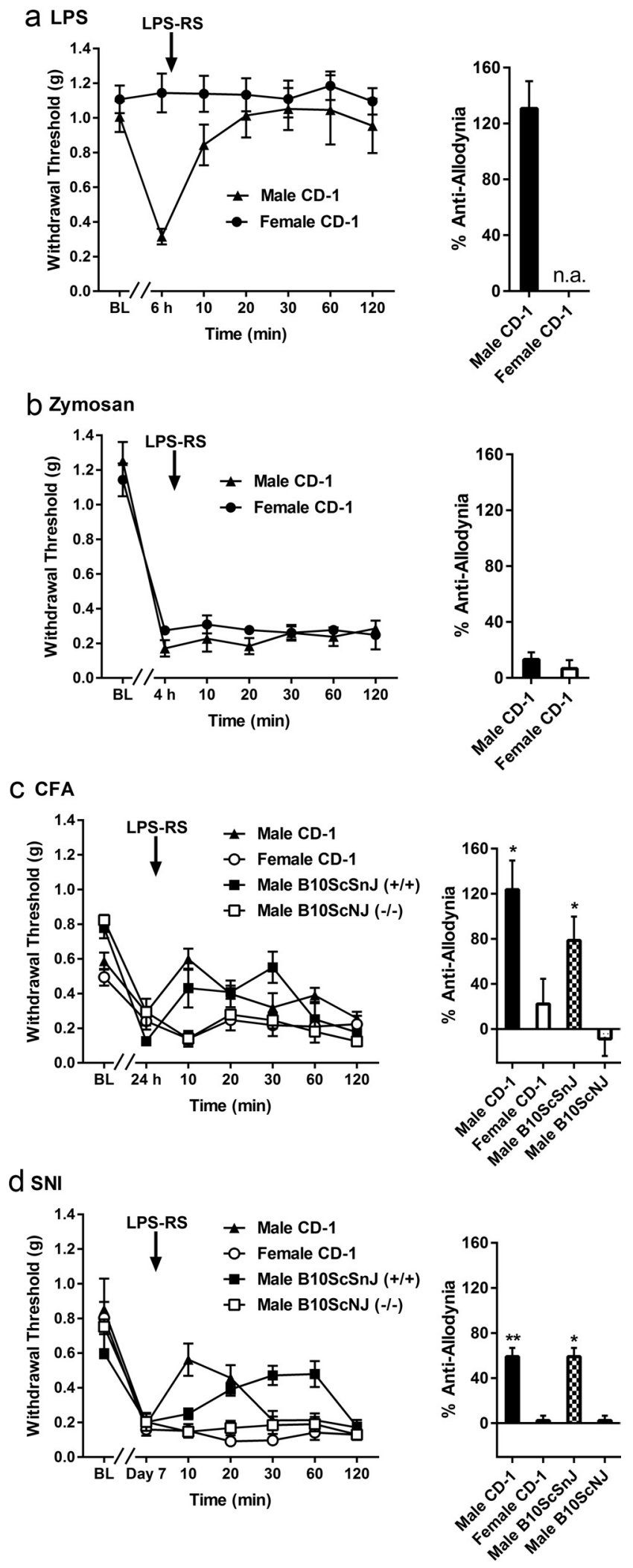

Figure 2. $\quad \boldsymbol{a}-\boldsymbol{d}$, Effects of pharmacological (LPS-RS) blockade of spinal TLR4 on mechanical allodynia induced by LPS (a), zymosan (b), CFA (c), and SNI (d) in male and female CD-1 mice, and male wild-type (B10SCSnj; +/+) and null mutant (B10ScNJ; - /-) mice. Symbols represent mean \pm SEM threshold $(\mathrm{g})$ to withdraw from von Frey filaments before injection or surgery [baseline (BL)], at the time point of maximal allodynia (see text), and 10-120 min after injection of $2 \mu \mathrm{g}$ (i.t.) LPS-RS. Bars represent mean \pm SEM percentages of maximum antiallodynia (i.e., reversal of allodynia already developed) by LPS-RS at any time point. ${ }^{*} p<0.05$, ${ }^{* *} p<0.01$ compared with opposite sex or opposite Trr4 genotype group by $t$ test.
B10ScSnJ (wild-type) mice (Fig. 2c). For SNI, repeated-measures ANOVAs revealed significant interactions with sex among CD-1 mice $\left(F_{(5,30)}=9.8, p<0.001\right)$ and with $\operatorname{Tl} 4$ genotype $\left(F_{(5,40)}=\right.$ $4.8, p<0.005)$; reversal of CFA allodynia was observed only in male CD-1 and male B10ScSnJ (wild-type) mice (Fig. $2 d$ ).

\section{Discussion}

We have discovered a surprising and robust sex difference in the involvement of spinal TLR4 in the mediation of chronic pain in mice, such that LPS allodynia in females after intrathecal administration was not observed. That this sex difference was never before observed for TLR4 is likely due to its specificity to pain and the spinal cord; very few extant TLR4 experiments have specifically involved the spinal cord. Our data reveal the existence of an, as yet unknown, TLR4-independent spinal pathway for pain processing in females.

Although some early studies suggested that TLR 2 might be a binding site for LPS, pure LPS-induced signal transduction is impaired by loss-of-function mutations of TLR4 (or of its adapter proteins MD-2 and CD14) but not of TLR2 (Beutler and Poltorak, 2001). Our data revealing no spinally mediated mechanical allodynia in the absence of testosterone thus can only be interpreted as a sex difference in spinal TLR4 involvement in pain. As there is no other route toward the development of mechanical allodynia in female mice or male TLR4 mutants after intrathecal LPS injection, no compensation is possible.

By contrast, although the TLR4/MD-2/CD14 complex has previously been implicated in neuropathic and inflammatory pain behavior in male rodents (Raghavendra et al., 2004; Tanga et al., 2005; Bettoni et al., 2008; Cao et al., 2009), it is obviously only one of many molecular players. Even among TLRs, TLR2 (Kim et al., 2007) and TLR3 (Qian et al., 2011) are also involved in chronic pain development. Thus, it is perhaps not surprising that Tlr4 null mutant B10ScNJ mice displayed equipotent allodynia from CFA and SNI compared with wild-type B10ScSnJ mice, although this finding is in direct contrast to those of Tanga et al. (2005). This might be due to the different nerve injuries used (SNI compared with L5 transection). However, that the efficacious and specific (Fig. 2a,b) TLR4 antagonist LPS-RS was able to reverse already-developed CFA and SNI allodynia in male CD-1 mice supports the contribution of TLR4 to chronic pain in male mice.

In the present study, spinal LPS-induced allodynia was reduced following testosterone removal and was reinstated with testosterone replacement in gonadectomized male and female mice. These findings, and the fact that no evidence of differential levels of spinal Tlr4 expression or TLR4 function in hypothermia were noted, suggest that female mice use a wholly TLR4independent pathway under normal circumstances, but that the TLR4-dependent pathway is still theoretically available, with testosterone acting as a "switch" between them. We have previously elucidated another "qualitative" sex difference-relevant to the neurochemical mediation of opioid analgesia and hyperalgesiainvolving NMDA receptors (in males) and melanocortin-1 receptors (in females) that also appears to work in this way (Mogil et al., 1993; 2003; Sternberg et al., 2004; Juni et al., 2010).

The molecular and cellular identity of the female TLR4independent system remains to be identified. Other TLRs (especially TLR2 and TLR3) are obvious candidates, and sex differences in TLR7 functioning have been noted (Berghöfer et al., 2006). Robust sex differences in both innate and adaptive immune system functioning have been noted in the autoimmune disease literature (Zandman-Goddard et al., 2007)—where like 
in chronic pain disorders women are the clear majority of patients (Berkley, 1997) —and thus it is possible that these sex differences might be relevant to pain processing as well. Epidemiological realities render the elucidation of this female system of substantially higher clinical relevance than that of the male, TLR4-containing pathway. The present observations further support the notion that the overwhelmingly common practice of omitting female subjects from preclinical studies (Mogil and Chanda, 2005; Zucker and Beery, 2010)—-despite clear and increasing evidence of sex differences in the fundamental mechanisms of pain-is associated with great risk of both drug development failures and failure to identify analgesic targets that would otherwise benefit the majority of pain sufferers.

\section{References}

Berghöfer B, Frommer T, Haley G, Fink L, Bein G, Hackstein H (2006) TLR7 ligands induce higher IFN- $\alpha$ production in females. J Immunol 177:2088-2096.

Berkley KJ (1997) Sex differences in pain. Behav Brain Sci 20:371-380.

Bettoni I, Comelli F, Rossini C, Granucci F, Giagnoni G, Peri F, Costa B (2008) Glial TLR4 receptor as new target to treat neuropathic pain: efficacy of a new receptor antagonist in a model of peripheral nerve injury in mice. Glia 56:1312-1319.

Beutler B, Poltorak A (2001) The sole gateway to endotoxin response: how LPS was identified as TLR4, and its role in innate immunity. Drug Metab Dispos 29:474-478.

Cao L, Tanga FY, Deleo JA (2009) The contributing role of CD14 in toll-like receptor 4 dependent neuropathic pain. Neuroscience 158:896-903.

Chaplan SR, Bach FW, Pogrel JW, Chung JM, Yaksh TL (1994) Quantitative assessment of tactile allodynia evoked by unilateral ligation of the fifth and sixth lumbar nerves in the rat. J Neurosci Methods 53:55-63.

Erridge C (2010) Endogenous ligands of TLR2 and TLR4: agonists or assistants? J Leukoc Biol 87:989-999.

Greenspan JD, Craft RM, LeResche L, Arendt-Nielsen L, Berkley KJ, Fillingim RB, Gold MS, Holdcroft A, Lautenbacher S, Mayer EA, Mogil JS, Murphy AZ, Traub RJ, IASP Consensus Working Group (2007) Studying sex and gender differences in pain and analgesia: a consensus report. Pain 132 [Suppl 1]:S26-S45.

Hylden JL, Wilcox GL (1980) Intrathecal morphine in mice: a new technique. Eur J Pharmacol 67:313-316.

Juni A, Cai M, Stankova M, Waxman AR, Arout C, Klein G, Dahan A, Hruby VJ, Mogil JS, Kest B (2010) Sex-specific mediation of opioid-induced hyperalgesia by the melanocortin-1 receptor. Anesthesiology 112:181188.

Kim D, Kim MA, Cho IH, Kim MS, Lee S, Jo EK, Choi SY, Park K, Kim JS, Akira S, Na HS, Oh SB, Lee SJ (2007) A critical role of toll-like receptor 2 in nerve injury-induced spinal cord glial cell activation and pain hypersensitivity. J Biol Chem 282:14975-14983.

Lan LS, Ping YJ, Na WL, Miao J, Cheng QQ, Ni MZ, Lei L, Fang LC, Guang RC, Jin Z, Wei L (2010) Down-regulation of Toll-like receptor 4 gene expression by short interfering RNA attenuates bone cancer pain in a rat model. Mol Pain 6:2.

Laursen SE, Belknap JK (1986) Intracerebroventricular injections in mice: some methodological refinements. J Pharmacol Methods 16:355-357.

Lehnardt S, Massillon L, Follett P, Jensen FE, Ratan R, Rosenberg PA, Volpe
JJ, Vartanian T (2003) Activation of innate immunity in the CNS triggers neurodegeneration through a Toll-like receptor 4-dependent pathway. Proc Natl Acad Sci U S A 100:8514-8519.

Meller ST, Dykstra C, Grzybycki D, Murphy S, Gebhart GF (1994) The possible role of glia in nociceptive processing and hyperalgesia in the spinal cord of the rat. Neuropharmacology 33:1471-1478.

Mogil JS, Bailey AL (2010) Sex and gender differences in pain and analgesia. Prog Brain Res 186:141-157.

Mogil JS, Chanda ML (2005) The case for the inclusion of female subjects in basic science studies of pain. Pain 117:1-5.

Mogil JS, Sternberg WF, Kest B, Marek P, Liebeskind JC (1993) Sex differences in the antagonism of swim stress-induced analgesia: effects of gonadectomy and estrogen replacement. Pain 53:17-25.

Mogil JS, Wilson SG, Chesler EJ, Rankin AL, Nemmani KV, Lariviere WR, Groce MK, Wallace MR, Kaplan L, Staud R, Ness TJ, Glover TL, Stankova M, Mayorov A, Hruby VJ, Grisel JE, Fillingim RB (2003) The melanocortin-1 receptor gene mediates female-specific mechanisms of analgesia in mice and humans. Proc Natl Acad Sci U S A 100:4867-4872.

Poltorak A, He X, Smirnova I, Liu MY, Van Huffel C, Du X, Birdwell D, Alejos E, Silva M, Galanos C, Freudenberg M, Ricciardi-Castagnoli P, Layton B, Beutler B (1998) Defective LPS signaling in C3H/HeJ and C57BL/ 10ScCr mice: mutations in Tlr4 gene. Science 282:2085-2088.

Qian NS, Liao YH, Feng QX, Tang Y, Dou KF, Tao KS (2011) Spinal toll like receptor 3 is involved in chronic pancreatitis-induced mechanical allodynia of rat. Mol Pain 7:15.

Raghavendra V, Tanga FY, DeLeo JA (2004) Complete Freund's adjuvantinduced peripheral inflammation evokes glial activation and proinflammatory cytokine expression in the CNS. Eur J Neurosci 20:467-473.

Shields SD, Eckert WA 3rd, Basbaum AI (2003) Spared nerve injury model of neuropathic pain in the mouse: a behavioral and anatomic analysis. J Pain 4:465-470.

Sternberg WF, Chesler EJ, Wilson SG, Mogil JS (2004) Acute progesterone can recruit sex-specific neurochemical mechanisms mediating swim stress-induced and kappa-opioid analgesia in mice. Horm Behav 46:467-473.

Tanga FY, Nutile-McMenemy N, DeLeo JA (2005) The CNS role of Tolllike receptor 4 in innate neuroimmunity and painful neuropathy. Proc Natl Acad Sci U S A 102:5856-5861.

Teghanemt A, Zhang D, Levis EN, Weiss JP, Gioannini TL (2005) Molecular basis of reduced potency of underacylated endotoxins. J Immunol 175:4669-4676.

Watkins LR, Martin D, Ulrich P, Tracey KJ, Maier SF (1997) Evidence for the involvement of spinal cord glia in subcutaneous formalin induced hyperalgesia in the rat. Pain 71:225-235.

Wiertelak EP, Smith KP, Furness L, Mooney-Heiberger K, Mayr T, Maier SF, Watkins LR (1994) Acute and conditioned hyperalgesic responses to illness. Pain 56:227-234.

Wu FX, Bian JJ, Miao XR, Huang SD, Xu XW, Gong DJ, Sun YM, Lu ZJ, Yu WF (2010) Intrathecal siRNA against Toll-like receptor 4 reduces nociception in a rat model of neuropathic pain. Int J Med Sci 7:251-259.

Zähringer U, Lindner B, Inamura S, Heine H, Alexander C (2008) TLR2promiscuous or specific? A critical re-evaluation of a receptor expressing apparent broad specificity. Immunobiology 213:205-224.

Zandman-Goddard G, Peeva E, Shoenfeld Y (2007) Gender and autoimmunity. Autoimmun Rev 6:366-372.

Zucker I, Beery AK (2010) Males still dominate animal studies. Nature 465: 690. 